\title{
LOS BAÑOS DE FORTUNA: \\ UN EJEMPLO DE TERMALISMO MEDIEVAL EN LA REGIÓN DE MURCIA
}

\author{
Jorge A. Eiroa Rodriguez ${ }^{1}$
}

\section{RESUMEN:}

El termalismo es un fenómeno constatado a lo largo de toda la Edad Media y los baños de Fortuna (Murcia) son un ejemplo paradigmático de la continuidad de esta práctica. Este artículo presenta distintos testimonios materiales y documentales que atestiguan el uso de la fuente termal tanto en época islámica como cristiana.

PALABRAS CLAVE: termalismo, Fortuna, baños.

\section{ABSTRACT:}

Thermalism is a well know phenomenon throughout the Middle Ages and the Fortuna spa can be considered as a paradigmatic example of this continuing practice. This articles deals with several documents and material testimonies that evidence the use of this thermal fountain both in the Islamic and Christian period.

KEY WORDS: thermalism, Fortuna, spa.

1 Becario de Investigación del Subprograma de Formación del Profesorado Universitario del M.E.C. y D., Departamento de Prehistoria, Arqueología, Historia Antigua, Historia Medieval y CC. y TT. HH. Facultad de Letras, Universidad de Murcia, c/ Santo Cristo, 1. C.P. 30.001, Murcia. 
La trascendencia del baño dentro del mundo islámico es sobradamente conocida. El hammam, a medio camino entre lo privado y lo público, resume la espiritualidad musulmana y su vida social; si bien constituye un imperativo religioso derivado de la necesidad del creyente de purificar su cuerpo como preludio a la purificación del alma, las funciones terapéuticas e higiénicas y el refinamiento en el arte de bañarse como exponente de la sociedad acomodada irían relegando a un papel secundario la función inicial de las abluciones rituales.

Con la llegada del dominio cristiano, las propiedades excepcionales del agua para la salud hicieron que los baños siguiesen proliferando, a fin de aprovechar este elemento constitutivo de vida y aglutinante de cultos. Eran fácilmente identificables y $\operatorname{conocidos}^{2}$, públicos y reglamentados y debían existir en todas las poblaciones hispanocristianas, asociados a una higiene que parecía no haber perdido importancia ${ }^{3}$. Ruiz-Moreno ya demostró que la ignorancia o el sectarismo habían difundido el falso "horror al baño" de la Edad Media ${ }^{4}$. Se divulgaron leyendas, como la que narraba que Alfonso VI destruyó los baños de su reino tras la derrota de Zalaca porque ablandaban el valor y el ímpetu de sus hombres, pero lo cierto es que las referencias a los baños públicos en los fueros de Calatayud, Usagre, Cáceres, Sepúlveda, Zorita de los Canes, Cuenca, Iznatoraf, Brihuega y en el Código de Tortosa, o algún fragmento literario, como el Exemplo XLIII de El Conde Lucanor hablan de una proliferación de estas instalaciones.

La costumbre de bañarse no era sólo urbana. Durante el período islámico, los habitantes de las zonas rurales frecuentaban el hammam con una regularidad similar a la de quienes poblaban las ciudades. Hay numerosos ejemplos de modestos baños islámicos de carácter rural, como los baños de la Zubia y Churriana, en la vega granadina, el baño de Jerez del Marquesado, los mencionados por al-Idrisi en las aldeas del Aljarafe sevillano o el más

2 M. SANTO TOMÁS PÉREZ, "El agua en la documentación eclesiástica", en $E l$ agua en las ciudades castellanas durante la Edad Media: fuentes para su estudio, de Val Valdivieso, M.A. (coord.), Valladolid, 1998, p. 27.

3 G. MENÉNDEZ PIDAL, La España del siglo XIII leída en imágenes, Madrid, 1986, p. 131 .

4 A. RUIZ-MORENO, "Los baños públicos en los fueros municipales españoles", Cuadernos de Historia de España 3 (1945), Buenos Aires, p. 152; L. TORRES BALBÁS, "Los baños públicos en los fueros municipales españoles", Al-Andalus 11 (1946), pp. 443445 . 
conocido de Torres Torres (Valencia), dado a conocer por Torres Balbás ${ }^{5}$. La continuidad en época cristiana de estos establecimientos rurales también está demostrada, con características similares; imitarían estructuralmente a los urbanos, si bien se nutrirían de sectores sociales distintos.

Sin embargo, si bien es habitual que el fenómeno del termalismo se asocie al mundo rural, es evidente que una cosa son los baños rurales anteriormente referidos y otra bien distinta son los baños minero-medicinales. Las evidentes dificultades a la hora de diferenciar el baño de carácter verdaderamente medicinal del baño entendido como simple reposo o higiene han provocado confusión terminológica. Faltan datos arqueológicos y, por encima de todo, las fuentes son muy confusas en este sentido, especialmente en el período islámico 6 .

En cualquier caso, el termalismo es un fenómeno constatado a lo largo de toda la Edad Media 7 . No sólo no hay duda sobre la ausencia de ruptura entre el período romano y el islámico ${ }^{8}$, sino que, como señala Cressier, parece que la conquista arábigo-beréber generó una verdadera expansión del uso de los baños termales y de las aguas minero-medicinales ${ }^{9}$. Aunque Guichard y Poisson han recordado acertadamente que el Islam excluye todo nexo entre el agua y lo sagrado ${ }^{10}$, los ritos de fertilidad constatados en las fuentes de Tetuán

5 L. TORRES BALBÁS, "El baño de Torres Torres (Valencia) y otros levantinos", $A l$ Andalus 17 (1952), 2, pp. 176-186.

6 El término hammam englobaba también los baños termales, como demuestra su pervivencia en las numerosas 'Alhamas' de nuestro territorio (Alhama de Almería, Alhama de Aragón, Alhama de Granada o Alhama de Murcia).

7 Sobre el termalismo medieval en el contexto europeo existe una dilatada bibliografía. Son especialmente interesantes los recientes trabajos de Gouédo-Thomas y Boisseuil, vid. C. GOUÉDO-THOMAS, "Le thermalisme médieval, de Flamenca à Michel de Montaigne, récits et images", en Villes d'eaux. Histoire du thermalisme, Actes du 117e Congrés national des sociétés savantes (Clermont-Ferrand, octubre 1992), París, pp. 11-26; D. BOISSEUIL, "Les stations thermales siennoises (XIII'-XVe siècles)", 2000 ans de thermalisme. Economie, patrimoine, rites et pratiques (coloquio, Puy-de-Dôme, marzo 1994), Aurillac, 1996.

8 I. VELÁZQUEZ SORIANO, G. RIPOLL LÓPEZ, "Pervivencias al termalismo y al culto a las aguas en época visigoda hispánica", Espacio, Tiempo y Forma, Serie II, 5 (1992), pp. 555-580.

9 P. CRESSIER, "Introducción”, Actas del I Congreso Peninsular de Termalismo Antiguo (Arnedillo, Octubre 1996), Casa de Velázquez-UNED, Madrid, 1997, pp. 523. 
en Marruecos por Valderrama y las conclusiones de las investigaciones arqueológicas de Ramírez Águila11, así como algunos testimonios escritos ${ }^{12}$, invitan a cuestionar la existencia de una ruptura. Todos los datos apuntan a que, al amparo de la religión oficial, subsistía una religiosidad popular que mantenía más vivas que nunca las reminiscencias de las antiguas culturas naturistas y que era la causante del sostenimiento de la importancia de las fuentes de aguas termales. Ahí están los conocidos ejemplos de Cefalà Diana (Palermo) ${ }^{13}$, Alhama de Granada ${ }^{14}$ o Alhama de Almería, conocidos por evidencias materiales y por referencias en las obras de al-Idrisi o Ibn Battuta. La continuidad de este fenómeno a lo largo de la Edad Media parece asegurada: los baños minero-medicinales seguirían siendo visitados no sólo por la población mudéjar, sino también por la cristiana y tanto sus conocidas cualidades como la permanente disponibilidad de agua caliente les permitirían pervivir durante siglos, en muchos casos hasta la actualidad.

En el Sureste de la península Ibérica, los baños minero-medicinales debieron ser abundantes durante la época islámica. No poseemos testimonios arqueológicos ni documentales sobre los de Archena y Mula, pero todo hace pensar que debieron estar en uso durante este período. La fuente mineromedicinal de Alhama de Murcia nos ha dejado, en cambio, importantes restos materiales y más documentación y, así, aparece mencionada por Al-Qazwini en el siglo XIII ${ }^{15} \mathrm{y}$, anteriormente, por Al-Idrisi ${ }^{16}$. Otro posible caso es el de

10 P. GUICHARD, J.M. POISSON, "Quelques éléments sur le thermalisme dans la Sicile et l'Espagne musulmanes", Espacio, Tiempo y Forma, Serie II, 5 (1992), p. 591.

11 J.A. RAMÍREZ ÁGUILA, "Baraka y termalismo en el al-Andalus y el Magreb. A propósito de los baños de Alhama de Murcia", Actas del I Congreso Peninsular de Termalismo Antiguo (Arnedillo, Octubre 1996), Casa de Velázquez-UNED, Madrid, 1997, pp. 545-554.

12 Es significativo el texto del escritor y político granadino Ibn al-Jatib en su libro de medicina, en el que estudia las ventajas de las aguas termales minerales junto a otros factores de la salud, como el coito o el sueño (recogido y comentado en M. de EPALZA, "Estructura y funciones de los baños islámicos”, en Baños árabes en el País Valenciano, Valencia, 1989, pp. 21-22).

13 A. BAGNERA, “Le cosidette 'Terme Arabe' di Cefalà Diana (Palermo): Relazione preliminare sulle indagini archaeologiche", en Terze Giornate Internazionali di Studi sull'area Elima, Pisa, 2000, pp. 57-78.

14 L. TORRES BALBÁS, Arte Almohade, Arte Nazarí, Arte Mudéjar, Ars Hispaniae IV, 1949, p. 158; R. MANZANO MARTOS, "El baño termal de Alhama de Granada", AlAndalus 23 (1958) 2, pp. 408-417. 
los baños del Azaraque (Argamón, Albacetei, cuyo uso en época medieval también parece estar constatado ${ }^{17}$.

Los baños de Fortuna (Murcia) ${ }^{18}$ también se enmarcan en la compleja configuración geológica del Sureste peninsular, un entorno especialmente propenso a exteriorizaciones geotérmicas ${ }^{19}$. Si bien conocemos algunos testimonios del poblamiento prehistórico de la zona en la que se sitúa el manantial ${ }^{20}$, el origen de los baños de Fortuna, a pesar de las habituales referencias míticas de los autores decimonónicos ${ }^{21}$, debe situarse en época romana, cuando las instalaciones experimentan una primera época de esplendor. Son habituales las referencias a los materiales de esta época encontrados allí durante el siglo XIX ${ }^{22}$, pero el verdadero descubrimiento del

15 Describe las instalaciones de baños como "las termas de Hamma Bi-Laqwar a 10 millas de la capital; se llamaban asi por estar en la alquería de Bi-Laqwar o Laqwar; en ella había recintos abovedados para hombres y mujeres, y el manantial nacía en el de aquellos con tanta agua que después de cubrir las necesidades de los bañistas podía regar los campos de la alquería".

16 Al-Idrisi menciona Hisn al-Hammam en su Nuzhat al-Mustaq, identificado por Baños Serrano como Alhama de Murcia. Vid. J. BAÑOS SERRANO, "Los baños termales minero-medicinales de Alhama de Murcia", Memorias de Arqueología 5 (1990), Murcia, p. 357.

17 M. LILLO CARPIO, A. SELVA INIESTA, "Consideraciones sobre los antiguos baños del Azaraque", Actas del I Congreso de Historia de Albacete, 1984, pp. 377-387.

18 Los baños de Fortuna están situados aproximadamente a $38^{\circ} 12^{\prime} 45^{\prime \prime} \mathrm{N}$ y $01^{\circ} 05^{\prime} 20^{\prime \prime}$ W, a 234 m.s.n.m., y se encuentran representados en la hoja $\mathrm{n}^{\circ}$ 892-III del mapa geográfico nacional a escala 1:25.000.

19 Para ampliar los aspectos geológicos e hidrológicos de los Baños de Fortuna y su entorno, vid. los distintos estudios recogidos en el volumen Estudios sobre el Balneario de Fortuna, (Memoria n ${ }^{\circ} 13$ ), Instituto de España, Real Academia de Farmacia, Madrid, 1987, 65 págs.; vid., asimismo, I. GENOVÉS CARDONA, A. MELCHOR SENENT, "Génesis geológica e hidrogeológica de la surgencia de aguas termales en los baños de Fortuna", en Espacio, Tiempo y Forma, Serie II, 5 (1992), pp. 455-482.

20 La referencia más antigua que encontramos en el entorno de los baños se enmarca en el Eneolítico (enterramiento colectivo de la Cueva del Barranco de la Higuera) y, posteriormente en el Castillejo o Castillico de los Baños, un yacimiento situado a 500 metros de los baños de la Edad del Bronce y de época ibérica.

21 A. LACORT, Ensayo monográfico razonado del agua minero-medicinal del Balneario de Fortuna, Valladolid, 1899 (reedición de 1991), p. 20. 
balneario romano tuvo lugar en $1988^{23}$. Numerosas investigaciones se sucedieron a partir de entonces ${ }^{24}$, alcanzando importantes resultados: en resumen, tras las excavaciones realizadas entre 1989 y 1999, se ha completado la planta de un gran edificio rectangular con compartimentaciones individuales, que en un primer momento del establecimiento termal que antecede al gran complejo que se encontraba bajo los Baños Viejos y comenzó a ser sacado a la luz en la reciente campaña de diciembre de $1999^{25}$, serviría de alojamiento a las personas que se desplazasen a los baños a tomar las

22 J. CHACEL TERRERO, Breve noticia sobre los baños termales de Fortuna, en la provincia de Murcia, Murcia, 1864, p. 1.

23 El responsable de este descubrimiento fue el profesor Philip Rahtz. Vid. L. WATTS, "El prof. Philip Arthur Rahtz, descubridor del Balneario de Fortuna", El balneario romano y la Cueva Negra de Fortuna (Murcia), Antigüedad y Cristianismo 13 (1996), pp. 553-565.

$24 \mathrm{Ph}$. RAHTZ, L. WATSS, A. GONZÁLEZ BLANCO, "Prospección de la zona de los antiguos Baños de Fortuna”, Memorias de Arqueología 4 (1989), pp. 152-154; Ph. RAHTZ, L. WATSS, A. GONZÁlEZ BLANCO, M. AMANTE SÁNCHEZ, "Excavaciones arqueológicas en Fortuna. Diciembre de 1990”, Memorias de Arqueología, 5 (1990), pp. 384391; A. GONZÁleZ BLANCO, M. AMANTE SÁNCHEZ, Ph. RAHTZ, L. WATSS, "Primer acercamiento a los restos arqueológicos del balneario romano", Espacio, Tiempo y Forma, Revista de la Facultad de Geografía e Historia de la UNED, serie II, 5 (1992), pp. 421-454; R. GONZÁLEZ FERNÁNDEZ, G. MATILLA SÉIQUER, F. FERNÁNDEZ MATALLANA, "La recuperación arqueológica del Balneario Romano de Fortuna", El balneario romano y la Cueva Negra de Fortuna (Murcia), Antigüedad y Cristianismo 13 (1996), pp. 179-220; M. LECHUGA GALINDO, "Hallazgos monetales en el yacimiento romano de baños de Fortuna", El balneario romano y la Cueva Negra de Fortuna (Murcia), Antigüedad y Cristianismo 13 (1996), pp. 221-224; P. VALLALTA MARTÍNEZ, "Informe sobre la restauración de varios objetos arqueológicos procedentes de los Baños de Fortuna", El balneario romano y la Cueva Negra de Fortuna (Murcia), Antigüedad y Cristianismo 13 (1996), pp. 543-546; A. GONZÁLEZ BLANCO, R. GONZÁLEZ FERNÁNDEZ, F. FERNÁNDEZ MATALLANA, "El balneario de Fortuna. Un caso arquetípico de continuidad cultural”, en Termalismo Antiguo. I Congreso Peninsular. Arnedillo (La Rioja), 3-5 de Octubre 1996 (Pérez Agorreta ed.), Madrid, 1997, pp. 319-328; G. MATILLA SÉIQUER, J. GALLARDO CARRILlO, A. EGEA VIVANCOS, "El Santuario romano de las aguas de Fortuna (el balneario de Carthago-Nova)", Mastia, en prensa; G. MATILLA SÉIQUER, J. GALLARDO CARRILLO, A. EGEA VIVANCOS, "Excavaciones arqueológicas en el balneario romano de Fortuna- campañas de abril y junio de 2000", Antigüedad y Cristianismo, 17, en prensa.

25 González Blanco, González Fernández y Fernández Matallana, ya habían anunciado la localización del gran conjunto termal y el manantial romano, al afirmar que "para encontrar el manantial y el establecimiento más importante romano es necesario excavar en el lugar de los Baños Viejos, ya que es allí donde floreció el balneario desde fines del siglo I hasta 1836", 
aguas $^{26}$. En este mismo entorno se sitúan la Cueva Negra de Fortuna ${ }^{27}$, el yacimiento de la Casa Roja de los Baños y algún hallazgo aislado de procedencia poco concreta ${ }^{28}$.

El estudio de la evolución de los baños de Fortuna a lo largo de la Edad Media resulta complejo, como consecuencia de la tradicional incapacidad de aislarlo del ya clásico debate en torno a la posible identificación de la Yusor islámica con la posterior Fortuna de los documentos castellanos, a la que tan indisolublemente unida permanece desde entonces. Mientras que el Canónigo Lozano apuntaba que se trataba de las termas de Balkur ${ }^{29}$ y Gaspar Remiro y Merino Álvarez identificaban Fortuna con Yusor $^{30}$, Vallvé Bermejo aceptaba esta última hipótesis basándose en una referencia a al-Maqqari relativa a las cesiones a Ibn Hud, pero planteaba la posibilidad de que Yusor fuese una transcripción vulgar de Itxar ${ }^{31}$. Aunque todavía sigue sin esclarecerse esta cuestión, en cualquier caso, la Yusor de las fuentes, de situarse en las proximidades de los baños, compartiría territorio con otros emplazamientos, que conforman un rico entorno arqueológico en la actualidad. Destacan,

vid. GONZÁlEZ BLANCO, A., GONZÁlEZ FERNÁNDEZ, R., FERNÁNDEZ MATALLANA, F., "El Balneario...”, p. 326.

26 La aparición del primitivo manantial romano en la última campaña de excavaciones podría relacionarse con el testimonio de Madoz, que afirma que "el manantial que existía anteriormente tenía su salida por una grieta o abertura en cantidad de una hila a borbotones y similando una palmera; el cual recogíase en una balsa llamada Baño de arriba de 4 varas de latitud y 8 de longitud, de aquella pasaba a otra en el que había asientos para comodidad de las personas que se metían y después se le daba salida para que beneficiase algunos trozos de tierra en el partido de Baños y Molinico", P. MADOZ, Diccionario geográfico-estadísticohistórico de España y sus posesiones de ultramar, Madrid, 1845-1850, p. 99.

27 Vid. la bibliografía recogida en VV.AA., El balneario romano y la Cueva Negra de Fortuna (Murcia), Antigüedad y Cristianismo 13 (1996).

28 J. MONTESINOS i MARTÍNEZ, "Terra sigillata procedente de Baños de Fortuna (Murcia), en el Museo de Elche (Alicante)", Verdolay 8 (1996), pp. 37-42.

29 J. LOZANO SANTA, J., Bastitania y Contestania del Reino de Murcia, Murcia, 1789 (ed. facsímil, Academia Alfonso X el Sabio, 1980), vol. 3, p. 107.

30 M. GASPAR REMIRO, Historia de Murcia musulmana, Zaragoza, 1905 (edición de la Academia Alfonso X el Sabio de 1980), p. 303; A. MERINO ÁLVAREZ, Geografía Histórica del territorio de la actual provincia de Murcia desde la reconquista por D. Jaime I de Aragón hasta la época presente, Madrid, 1915 (Reproducción de 1981, Academia Alfonso X el Sabio, Murcia), p. 35.

31 J. VALLVÉ BERMEJO, "La división territorial en la España Musulmana (II)", $A l$ Andalus. Revista de las Escuelas de Estudios Árabes de Madrid y Granada 37 (1972), p. 168. 
principalmente, dos yacimientos medievales que deben ser entendidos en relación con las aguas termales: por un lado, la Torre Vieja o Castillo de los Moros, a 1,6 km al sur de Fortuna, que presenta restos de una torre de muros encofrados de cal y piedra y ha ofrecido interesantes materiales cerámicos ${ }^{32}$; por otro, el Castillico de las Peñas, situado en un paraje que servía de comunicación entre el llano de Fortuna y la zona de la sierra, controlando los accesos a la fuente termal, de la que sólo dista $4 \mathrm{~km}$ y que, además de tener importantes restos de estructuras en superficie, ha ofrecido abundantes materiales arqueológicos 33 .

32 J. NAVARRO PALAZÓN (coord), La cerámica islámica en Murcia, (Catálogo de la exposición de 1986, Murcia), Murcia, 1986, pp. 37-38; G. MATILLA SÉIQUER, I. PELEGRÍN GARCÍA, "Contexto arqueológico de la Cueva Negra de Fortuna", La Cueva Negra de Fortuna (Murcia) y sus Titvili Picti. Un santuario de época romana, Antigüedad y Cristianismo 4 (1987), pp. 122-123.

33 A. FERNÁNDEZ AVILÉS, "Reseña de los fondos principales del Museo de Murcia: la arqueología murciana a través del Museo Arqueológico Provincial", Memoria de los Museos Arqueológicos Provinciales, 1941, p. 109; I. ALBERT BERENGUER, “Objetos de bronce anterromanos e hispanorromanos del Museo de Murcia", Memoria de los Museos Arqueológicos Provinciales, 1942, p. 155; A. FERNÁNDEZ AVILÉS, "Tonel ibérico del Castillico de las Peñas", Anuario Español de Arqueología, 15 (1942), pp. 173-174; J. CRESPO GARCÍA, "Estación ibérica del castillo de las Peñas (Fortuna, Murcia)", Crónica del IV C.A.S.E., Elche, 1948, pp. 238-243; A. GARCÍA BELLIDO, Hispania Graeca, Barcelona, 1948, II, p. 177; M. JORGE ARAGONESES, Museo Arqueológico de Murcia, Madrid, 1956, p. 44; D. FLETCHER VALLS, “Toneles cerámicos ibéricos", Archivo de Prehistoria Levantina, 6 (1957), pp. 115-116 y 145-147; E. DIEHL, P. SAN MARTÍN, H. SCHUBART, "Los Nietos. Ein Handelsplatz des 5 bis 3 Jahrhunderts an der Spanischen Levanteküste", Madrider Mitteilungen 3 (1962), p. 73; G. TRIAS, Cerámicas griegas de la península ibérica, Valencia, 1970, pp. 409-410; P. LILLO CARPIO, "Consideraciones sobre un instrumento musulmán de posible aplicación geodésica", Papeles del Departamento de Geografía, 8, 1978-79, pp. 229-240; P. LILLO CARPIO, "Cantimploras y toneles de cerámica ibérica en el área murciana”, Rev. Murcia 16 julio-diciembre 1979), pp. 26-29; P. LILLO CARPIO, "Acerca de unos materiales árabes procedentes del Castillico de las Peñas, Fortuna (Murcia)”, Miscelánea Medieval Murciana 6 (1980), pp. 275-284; J.M. GARCÍA CANO, Cerámicas griegas de la Región de Murcia, Murcia, 1982, pp. 123-129; P. LILLO CARPIO, El poblamiento ibérico en Murcia, Murcia, 1981, pp. 217-248; A. INIESTA SANMARTÍN, Las fibulas de la región de Murcia, Murcia, 1983, pp. 186-188; J. NAVARRO PALAZÓN (Coord.), La cerámic ..., pp. 24-37. G. MATILLA SÉIQUER; I. PELEGRÍN GARCÍA, "Contexto arqueológico...", pp. 117-120; S. ALONSO NAVARRO, Libro de los castillos y fortalezas de la Región de Murcia, Murcia, 1990, p. 161; A. GONZÁLEZ BLANCO, R. GONZÁlEZ FERNÁNDEZ, F FERNÁNDEZ MATALLANA, "El balneario...", pp. 325-326. 
Lacort aporta alguna información interesante sobre los baños de Fortuna al referirse a un edificio rodeado de pequeñas casas que, levantado sobre restos más antiguos, él no duda en identificar como islámico por su "forma de construcción" y que habría existido hasta hace poco tiempo ${ }^{34}$. La descripción que realiza del conjunto es muy interesante ${ }^{35}$ y deberíamos preguntarnos si realmente estamos realmente ante unos "baños moros", como él afirma, o simplemente está detallando los baños de la Edad Moderna. Nos inclinamos por la segunda posibilidad, puesto que las características del edificio coinciden con algunas de las descripciones registradas en los expedientes de arrendamiento de los baños de los siglos XVIII y XIX y parece difícil una pervivencia de las estructuras islámicas hasta época tan tardía teniendo en cuenta la fragilidad de las construcciones de este tipo. No obstante, es evidente que distintos hallazgos islámicos fueron constatados por Chacel en 1864, pues hace referencia en su obra a "los monumentos y vestigios hallados del tiempo de los árabes" ${ }^{\prime 6}$, por Carrió Grifol en $1871^{37}$, y más recientemente por Ramírez Águila, que ha insistido en el uso de los baños de Fortuna en época islámica, resaltando su similitud con los de Alhama ${ }^{38}$.

Las excavaciones arqueológicas del balneario romano realizadas en los últimos diez años por el equipo del profesor González Blanco así lo han confirmado. Entre las siete fases de ocupación del yacimiento, distribuidas cronológicamente en función de la estratigrafía resultante de las áreas y unidades de habitación existentes en el gran edificio rectangular con

\section{A. LACORT Y RUÍZ, Ensayo..., p. 21.}

35 "El edificio constaba de dos plantas, baja y alta, ó mejor dicho, de piso bajo y sótano; el piso bajo estaba divido en dos apartamentos, una especie de portal ó entrada que podía servir de vaporario, pues a la izquierda de la puerta de entrada tenía comunicación directa con la planta baja, tal vez para ventilación del baño y gran vaporario. Detrás de él había una escalera en rampa de tres tramos para bajar á un sitio que, indudablemente, era un gran vaporario, y que tal vez servía para vestirse y desnudarse, é inmediato al baño, constituido de grandes piedras solamente superpuestas y desiguales, y aunque conociéndose que era de más moderna construcción, cubierto por un techo abovedado".

36 J. CHACEL TERRERO, Breve noticia..., p. 1.

37 J. CARRIÓ GRIFOL, Memoria reglamentaria anual del Balneario de Fortuna, Fortuna, 1871, p. 5.

38 J.A. RAMÍREZ ÁGUILA, J.A., "Los baños islámicos de Murcia”, en Guía Islámica de la Región de Murcia, Murcia, 1990, p. 109. 
compartimentaciones que se exhumó en las últimas campañas, se encuentra la fase II. Esta fase de ocupación, en realidad la sexta si atendemos al orden cronológico, se identificó a partir del enterramiento encontrado en la unidad de habitación 139: estaba compuesto por las unidades estratigráficas 1101, 1102 y 1103, y cortaba el pavimento de una estancia a la altura del umbral; la fosa (u.e. 1101) tenía unas dimensiones de 1,43 x 0,92 $\mathrm{m}$ y una profundidad de $0,21 \mathrm{~m}$ Se trataba del enterramiento de un hombre adulto (u.e. 1102) orientado hacia el sur, con la cabeza hacia el oeste y depositado en decúbito lateral, con las extremidades superiores e inferiores dobladas en una posición fetal muy forzada. Tanto la orientación y posición del cuerpo como la aparición de un pequeño fragmento de cerámica en el interior de la caja torácica han hecho que sea inscrito dentro de un impreciso contexto de época islámica.

Por otro lado, en la campaña arqueológica realizada en diciembre de 1999 en el mismo yacimiento, pero en un área mucho más próxima al supuesto emplazamiento de los baños islámicos, han sido muy numerosos los fragmentos hallados de cerámica de este período ${ }^{40}$, y un mapa de 1868 que fue presentado para solicitar la ampliación de temporada del nuevo balneario ${ }^{41}$, registra unos restos en superficie que su autor identifica como baños árabes; posiblemente fueron confundidos con los restos romanos pero, en cualquier caso, confirman la existencia de una fuerte tradición oral que refleja la utilización de los baños en este momento y Olmos Herguedas ha demostrado hasta qué punto la tradición oral puede ser decisiva en el estudio del agua en la época medieval ${ }^{42}$.

El carácter de este asentamiento islámico de los baños de Fortuna sería prácticamente marginal, a juicio de Patrice Cressier, que ha afirmado que en los casos de fuentes que manan en zonas rurales muy aisladas, los bañistas se

39 R. GONZÁLEZ FERNÁNDEZ, G. MATILLA SÉIQUER, F. FERNÁNDEZ MATALLANA, “La recuperación...”, p. 194.

40 Información facilitada por el profesor Matilla Séiquer, director de los trabajos arqueológicos de campo, a quien agradezco su colaboración.

41 A. LÓPEZ ROCHA, Balneario de Fortuna, Cátedra de Hidrología Médica de la Universidad Complutense de Madrid, Tesis Doctoral, 1998, p. 116.

42 E. OLMOS HERGUEDAS, "Fuente oral y etnohistoria en el estudio del agua durante la Baja Edad Media", en El agua en las ciudades castellanas durante la Edad Media: fuentes para su estudio, de Val Valdivieso, M.A. (coord.), Universidad de Valladolid, Valladolid, 1998, pp. 207-240. 
limitan a una población con escasos recursos, el impacto económico es casi nulo y sus instalaciones reducidas o inexistentes ${ }^{43}$. González Blanco y su equipo son de la misma opinión, pues si bien reconocen que el pueblo, empujado por sus viejas creencias ancestrales y mágicas y por su conocimiento del valor terapéutico del agua, debió seguir usando los baños, no dudan en afirmar que ese uso debía ser residual y poco significativo. En cualquier caso, la continuidad del establecimiento termal durante la época de dominio islámico está garantizada, tanto por los hallazgos arqueológicos como por alguna referencia documental, como la de una carta de 1505 en la que la pretendida señora de Fortuna, doña Isabel de Orumbella, se queja de que los vecinos de Abanilla y Fortuna "van a la fuente e baños de Fortuna donde viene el agua para el dicho molino" y se bañan, "segund que seyendo moros lo fazían"44.

La situación del establecimiento termal sufrió algunos cambios con la conquista cristiana. El proyecto continuista de Alfonso X supuso la adopción del legado islámico y el traspaso de la mayor parte de los baños que, salvo algunas excepciones ${ }^{45}$, siguieron utilizándose 46 , como ya se ha explicado, especialmente si tenían un carácter minero-medicinal. Con la entrega por parte del soberano castellano de unos territorios al hasta entonces rey de Murcia a cambio de su colaboración político militar comienza una nueva fase en la historia de los baños de Fortuna. Gracias a los documentos que registran la venta de las propiedades territoriales que quedaban en manos musulmanas a finales del siglo XIII y a la luz del cotejo de fuentes islámicas y cristianas no tenemos dudas de que entre los territorios entregados se encontraban

43 P. CRESSIER, “Introducción...”, p. 525.

44 Archivo Municipal de Murcia (A.M.M.), Caja 12, núm. 35; vid. Apéndice Documental.

45 Se han documentado algunos ejemplos de ruptura, como la que parece desprenderse de la donación de unos "viejos baños" ilicitanos a los mercedarios de Santa Eulalia en 1271 para su transformación en capilla, vid. J. TORRES FONTES (ed.), Documentos del siglo XIII, CODOM 2, Murcia, 1969, p. 37.

46 Puede servir de ejemplo el caso de los llamados baños de la reina, bien conocidos gracias a un extraordinario documento de 1391 que, además de demostrar la continuidad, describe usos y características, vid. Archivo de la Catedral de Murcia (A.C.M.), perg. n 108, analizado en J. TORRES FONTES, "Los baños de la Reina", Murgetana 40 (1975), pp. 6374. Vid., asimismo, M. MARTÍNEZ MARTÍNEZ, "Control, usos y defensa del agua en Murcia (siglos XIII-XV)”, en El agua en la Historia, Salamanca, 1998, p. 14. 
Fortuna y sus baños ${ }^{47}$. Estos documentos representan la primera referencia documental de Fortuna, ya que no había sido mencionada en los documentos de la ocupación alfonsí ni en la lista de las fortalezas entregadas a los mandos de la hueste castellana.

Así, sabemos que el 27 de febrero de 1297, Fernando IV autorizaba tardíamente a Ibrahim Abu Ishaq, denominado por los cristianos "rey de los moros de la Arrexaca de Murçia" para que vendiera sus propiedades ${ }^{48}$, siguiendo las directrices marcadas en 1293 por Sancho IV. Ibrahim Abu Ishaq Ibn Hud, que cerraba la intitulación real islámica en Murcia, le había vendido Fortuna a Aparicio de Nompot dos años antes, el 3 de junio de 1295, por un precio de 3.000 maravedíes, y en esta venta iban incluidos, como no podía ser de otra manera, los baños ${ }^{49}$. De esta forma, Fortuna se convertía en señorío cristiano. La venta, ya recogida por Lacort (aunque erróneamente fechada ${ }^{50}$ ), había sido hecha por Aparicio de Nompot en nombre de su yerno Pedro Gueralt, probablemente por ausencia del último, y así lo confirmaba el propio comprador el 11 de marzo de $1296^{51}$; fue completada con la confirmación real de abril de 1307 mediante la cual Fernando IV aprobaba y reafirmaba todo lo escrito y acordado 52 . Ese mismo año, el monarca concedía, por privilegio rodado, los territorios de Guerao a la Orden de Santiago en atención a los

47 J. TORRES FONTES, "Fortuna en los siglos XIII y XIV (Notas y documentos para su historia)", Murgetana 28 (1968), pp. 52-55.

48 A.M.M., Perg. n 83; Cart. Real 1352-82, Eras, fol. 176 r.; Libro de Privilegios, fol. 49; en J. TORRES FONTES, "Fortuna...", pp. 71-72; J. TORRES FONTES (ed.), Documentos de Fernando IV, CODOM V, Murcia, 1980, p. 1. Torres Fontes ha rechazado por incoherentes las otras dos fechas que se barajaban para esta carta real, 27 de febrero de 1295 y 27 de febrero de 1296, vid. J. TORRES FONTES, "Fortuna...”, p. 57.

49 A. M. M., Perg. n 83; Cart. Real 1352-82, Eras, fol. 176; Libro de Privilegios, fol. 49; en J. TORRES FONTES, “Fortuna...", pp. 68-69; J. TORRES FONTES (ed.), Documentos del Siglo XIII, CODOM, II, Murcia, 1969, pp. 108-109.

50 Lacort sitúa el suceso en 1333, vid. A.LACORT Y RUIZ, Ensayo monográfico..., p. 21.

51 A.M.M., Perg. $n^{\circ} 83$; Cart. Real 1352-82, Eras, fol. 176 v.; Libro de Privilegios, fols. 46 v.-47 r.; en J. TORRES FONTES, "Fortuna...”, pp. 70-71; J. TORRES FONTES (ed.), Documentos del Siglo XIII, CODOM, II, Murcia, 1969, pp. 120-121.

52 A.M.M., Perg. 83; Cart. Real 1352-82, Eras, fols. 176-177; Libro de Privilegios, fols. 46 r.-48 r.; J. TORRES FONTES, "Fortuna...”, pp. 72-74; J. TORRES FONTES (ed.), Documentos de Fernando IV, CODOM V, Murcia, 1980, pp. 72-74. 
servicios prestados, provocando así una situación ${ }^{53}$ producto de la desinformación que no llegaría a tener validez por la prohibición de vender bienes territoriales a Órdenes Militares e Iglesia. ${ }^{54}$.

La situación se estabilizó relativamente y los baños, de los que no tenemos noticias expresas, comenzaron a tener un titular firme, a pesar de que los problemas de repoblación, habituales en ese momento de reorganización, no parecían solucionarse. La inseguridad permanente, acrecentada por la ocupación aragonesa del territorio murciano a finales del siglo XIII, se tradujo en una concentración de la escasa población en los núcleos fortificados y en un lógico abandono del mundo rural ${ }^{55}$; en este contexto, los señores de Fortuna, los Guerao, como acertadamente explica Torres Fontes ${ }^{56}$ se emplearon más en ostentar su señorío que en promover la repoblación y esto, sin lugar a dudas, debió repercutir en la afluencia de gentes hasta la estación termal. En cualquier caso, nada sabemos de los intentos de repoblación ni del estado en que se encontraban los baños, que han aportado algún hallazgo numismático significativo para el estudio de este período 57 .

A la muerte de Juan Guerao, su sobrino, Pedro Guerao, recibió el señorío de Fortuna como herencia, si bien las pretensiones del segundo esposo de Francisca Escorceyn, que intentaba recuperar la dote aportada en primeras nupcias, provocó la venta de "la heredat et termino que dizen Fortuna, que

53 Archivo Histórico Nacional (A.H.N.), Uclés, Hechar, caxon 50, núm. 13; en J. TORRES FONTES, "Fortuna...", pp. 74-78; J. TORRES FONTES (ed.), Documentos de Fernando IV, CODOM V, Murcia, 1980, pp. 78-79.

54 Una carta de junio de 1308 revocaba la donación y devolvía la propiedad a la familia Guerao. A.M.M., Libro de Privilegios, fol. 49 r.; Libro I , fols. 95 v.-96 v; en J. TORRES FONTES, "Fortuna...", pp. 78-79; J. TORRES FONTES (ed.), Documentos de Fernando IV, CODOM V, Murcia, 1980, p. 85)

55 Esta situación debe ponerse en relación con una carta emitida por Fernando IV en noviembre de 1311, por la cual prometía concederle a Pedro Guerao la capitación de los moros que se asentasen en Fortuna si llevaba a cabo su repoblación, como respuesta a una petición del propio señor de Fortuna. A.M.M., Cart. Real 1352-82, Eras, fol. 177 r.; en J. TORRES FONTES, "Fortuna...", pp. 79-80; J. TORRES FONTES (ed.), Documentos de Fernando IV, CODOM V, Murcia, 1980, pp. 110-111.

56 J. TORRES FONTES, "Fortuna...", p. 50.

57 Un dinero de Jaime II de Aragón acuñado en Barcelona, todavía en proceso de estudio (dato transmitido por el doctor Matilla Séiquer). 
está yerma" 58 . El concejo de Murcia, adelantándose al de Molina, aprovechó la oportunidad y por un precio de 4.000 maravedíes, a través el jurado clavario Pedro Jufré, adquirió "la dicha Fortuna con todos sus terminos et con los bannos que en ella son" 59 , tomando posesión real el 16 de noviembre de 137960; se transformaba, de esta forma, su condición jurisdiccional: el señorío pasaba a formar parte del concejo de Murcia y, en adelante, los "señores de Fortuna" serían sus censatarios y no sus propietarios, ya que en 1404 el concejo acordaba entregar el término de Fortuna a censo en pública convocatoria, a fin de garantizar su definitiva puesta en valor. Esta entrega recoge la primera referencia documental detallada ${ }^{61}$ sobre los baños, una inclusión que no hace sino confirmar la suposición de que no hubo ruptura entre la época islámica y el mundo cristiano posterior y las instalaciones termales, aunque más humildemente que en época romana, habían seguido utilizándose y seguían siendo conocidas pese al abandono que las rodeaba ${ }^{62}$.

58 Se acordó su venta y se efectuó su entrega en agosto de 1379. A.M.M., Colección Libros Manuscritos (1262-1849), n 37 (cuaderno en pergamino, con hilos de seda en colores y capital inicial en rojo), fols. 1 v.-8 r.; en J. TORRES FONTES, “Fortuna...”, pp. 81-102.

59 A.M.M., Colección Libros Manuscritos (1262-1849), $\mathrm{n}^{\circ} 37$ (cuaderno en pergamino, con hilos de seda en colores y capital inicial en rojo), fols. 1 r.-10 v.; en J. TORRES FONTES, "Fortuna...", pp. 81-102. Vid., asimismo, A.M.M., Act. Cap. 1379, fol. 82 r.-v.; en F. VEAS ARTESEROS (ed.), Documentos del siglo XIV, CODOM XII, Murcia, 1990, pp. 35-36.

60 A.M.M., Colección Libros Manuscritos (1262-1849), $\mathrm{n}^{\circ} 37$ (cuaderno en pergamino, con hilos de seda en colores y capital inicial en rojo), fol. 9 v.; en J. TORRES FONTES, "Fortuna...", pp. 81-102.

61 Algunas referencias aisladas se pueden localizar en documentos anteriores. Por ejemplo, en 1383 el concejo de Murcia daba licencia a los ganados del concejo de Villena para que pudiesen ir al Campo de Cartagena "por el termino de nuestro lugar de Fortuna, por ençima de los baños”; A.M.M., Act. Cap. 1382, fol. 118 r.-v.; en M.C. VEAS ARTESEROS, "Notas para el estudio de la ganadería del Marquesado de Villena", en Congreso de Historia del Señorío de Villena, Albacete, 1987, p. 421; F. VEAS ARTESEROS (ed.), Documentos del siglo XIV-3-, CODOM XII, Murcia, 1990, pp. 178-180.

62 "Et por quanto la dicha Fortuna está yerma et malparada tienpo ha, en tal manera que la dicha çibdat non ha rentas nin prouechos algunos della, por esta razon el dicho conçeio, caualleros, escuderos, offiçiales et omes buenos ordenaron et mandaron a Remir Sanchez de Madrit, su jurado clauario, que ponga en almoneda publica a correr por assenssamiento la dicha heredat et termino de la dicha Fortuna con todos sus terminos, pastos et derechos, et bannos et agua dellos, a la dicha Fortuna pertenesçientes", A.M.M., Colección Libros Manuscritos (1262-1849), nº 37 (cuaderno en pergamino, con hilos de seda en colores y capital inicial en rojo), fols. 10 r.-10 v.; en J. TORRES FONTES, "Fortuna...", pp. 81-102. 
Al establecer las condiciones relativas a la repoblación, la justicia, la protección, etc. se advierte "que todos los vezinos et moradores de la dicha çibdat et de qualesquier logares de la comarca que fueren o quisieren yr a los bannos de la dicha Fortuna a se bannar, que lo puedan fazer francamente et quita et libre que non paguen derecho nin tributo alguno a la dicha çibdat nin al dicho Lope Garçia nin a otro alguno que assensare la dicha heredat de Fortuna"63; esta decimocuarta condición de acensamiento confirma que, pese a las innegables condiciones de abandono y pobreza en las que se encontraba Fortuna, que ni siquiera era merecedora de otra denominación documental que la de logar, la población de la comarca continuaba acercándose a tomar las aguas con una frecuencia relativamente importante.

El concejo otorgó la concesión de los baños de Fortuna y su correspondiente carta de acensamiento a Lope García de Zafra, que había ofrecido 2.700 maravedíes anuales y los baños volvieron a aparecer expresamente mencionados en la carta de acensamiento ${ }^{64}$. Fortuna pasó, con sus baños, a ser el censo más importante de cuantos recibía Murcia 65 .

En otro sentido, los baños también desempeñaron un papel importante en las disputas con la vecina localidad de Abanilla. La entrega en censo de Fortuna supuso, en cierta medida, el comienzo de una lucha por el territorio, motivada por la imprecisa fijación de los términos. Desde un principio el conflicto se centró en la propiedad de Cañada Hermosa, con significativos episodios de violencia ${ }^{66}$, y las aspiraciones de Fortuna y Abanilla de obtener

63 A.M.M., Colección Libros Manuscritos (1262-1849), nº 37 (cuaderno en pergamino, con hilos de seda en colores y capital inicial en rojo), fol. 11 v.; en J. TORRES FONTES, "Fortuna...", pp. 81-102.

64 "Otorgamos que estableçemos de nueuo a çienso et çierta venta a mejorar et en alguna cosa non peorar a vso et costunbre de buenos çensaleros a vos, el dicho Lope Garçia, que presente sodes, por vos et en nonbre del dicho Ferrand Lopez, vuestro fijo, que es absente, el dicho logar et heredades de regadio con su agua et aluares de Fortuna, con todos sus terminos et con los bannos que en ella son, segunt es todo afrontado en la carta de la vendida judiçial que fue fecha de la dicha Fortuna", A.M.M., Colección Libros Manuscritos (1262-1849), no 37 (cuaderno en pergamino, con hilos de seda en colores y capital inicial en rojo), fol. 14 v.; en J. TORRES FONTES, “Fortuna...”, pp. 81-102.

65 A.L. MOLINA MOLINA, El campo de Murcia en el siglo XV, Murcia, 1989, p. 75.

66 Un buen ejemplo son los que en 1427 protagonizó Alfonso Fajardo, futuro Fajardo "el Bravo" e hijo de la señora de Fortuna, Constanza Fernández Mexía, vid. A.M.M., Act. Cap. de 1427, sesión de 22 de noviembre; en J. TORRES FONTES, El Señorío de Abanilla, Murcia, 1982, p. 66. 
las mejores tierras de la comarca afectaron a las instalaciones termales. El 14 de mayo de $1405^{67}$ el concejo de Murcia decide enviar una expedición de setenta y un hombres a caballo y sesenta y cuatro hombres a pie (peones, ballesteros y lanceros), comandados por el alcalde y los jurados de la ciudad, para derribar "una casa que los moros de Hauaniella auian fecho en los bannos de Fortuna"68. Si bien no existen dudas sobre el éxito de la expedición, que luchaba tanto por recuperar el manantial termal como por no perder el principal recurso hídrico del riego de la zona, lo cierto es que tan sólo dos años después el concejo de Murcia ordenó al censatario de Fortuna, Lope García de Zafra, cerrar con tapias y puertas los baños de Fortuna "e que los defienda de los vezinos de Hauanilla que se non bañen en ellos"69.

Las disensiones se retomaron en 1473, tras la extraña muerte de tres habitantes de Abanilla a causa de "muy crudas y feas lançadas"70. Se volvió a caer en disputas territoriales en torno a la propiedad de algunos términos limítrofes ${ }^{71}$ y la solución de esta contienda territorial supuso la reafirmación de los baños termales como propiedad de Fortuna. Álvaro de Santisteban, bachiller en decretos y alcalde mayor del adelantamiento, y el enviado del maestre de Calatrava, por cada una de las dos partes en litigio, efectuaron el decisivo amojonamiento de las respectivas jurisdicciones el 15 de abril de 1474, delante de dos escribanos y diferentes testigos, sobre el mismo terreno de disputa; la colocación de los mojones decimoprimero (situado en la parte superior del almarjal de los Baños de Fortuna y de la rambla de dicho almarjal), decimosegundo (emplazado "en la vertiente frente a levante", en lo alto de un cerro frente a los baños) y decimotercero (el que daba fin al amojonamiento, levantado "a la parte de levante, a la falda de dicho cabezo de los Baños") 72 terminaba para siempre con cualquier pretensión de Abanilla

67 A.M.M., Act. Cap. de 1405, sesión de 14 de mayo.

68 No obstante, es interesante señalar que, en la carta que el corregidor Juan Rodríguez de Salamanca envía al concejo de Murcia desde Lorca aconsejándoles el derribo y otorgándoles permiso para ello, se hace referencia a más de una construcción: "los de Hauaniella que hedeficaron de nueuo casas en vuestro termino". A.M.M., Act. Cap. de 1405, sesión de 14 de mayo, carta inserta de 13 de mayo de 1405.

69 A.M.M., Act. Cap. de 1407, sesión de 22 de noviembre; en J. TORRES FONTES, El Señorío ..., p. 66.

70 J. TORRES FONTES, El Señorío..., p. 109.

71 A.M.M., Act. Cap. de 1474, en J. TORRES FONTES, El Señorío..., p. 115.

72 A.M.M., Act. Cap. de 1475, en J. TORRES FONTES, El Señorío.., p. 117. 
hacia los baños de aguas termales. A pesar de que en 1488 se reanudó la disputa en torno a la posesión de la Cañada de la Contienda entre las dos poblaciones $^{73}$ (que todavía seguía pendiente en 1498 ante la Audiencia de Ciudad Real ${ }^{74}$ ) y más tarde el conflicto se traspasó a la cañada de la Alheña y a otras cuestiones, nunca se pusieron en tela de juicio los derechos jurisdiccionales de Murcia (y, por lo tanto, de Fortuna) sobre los baños. La cordialidad se abrió paso paulatinamente, al surgir las figuras de los árbitros o mediadores entre ambos concejos ${ }^{75}$, poniendo fin a la secular hostilidad, que constituye una constante en ésta época: los municipios luchan por que se les reconozca el acceso y la propiedad de determinadas fuentes que sirven, frecuentemente, de límites territoriales ${ }^{76}$ y los litigios tienden a complicarse indefinidamente ${ }^{77}$.

En diciembre de 1466 Pedro Fajardo, adelantado mayor del reino de Murcia, vendía a Juan Cascales, regidor de la capital, "el lugar de Fortuna de los baños (...) que agora es poblado de moros e crisptianos"78. Poco tiempo después, entre 1483 y 1489, tenía lugar un pleito entre doña Leonor Manrique, viuda del antiguo censatario ${ }^{79}$, y el propio Juan Cascales, regidor de la capital, en torno a la posesión de Fortuna y, consiguientemente, de sus baños. Este pleito, abundantemente documentado ${ }^{80}$, se resolvió en 1489 , confirmando los derechos del hijo de Juan de Cascales en la persona de Francisco Cascales, su

73 A.M.M., Legajo 1525; caja 3713/101; caja 5/67, 68 у 69; legajo 3713/102; у caja 3713/50; J. TORRES FONTES, El Señorío..., pp. 134-138.

74 A.M.M., leg. 1525; en J. TORRES FONTES, El Señorío..., p. 134.

75 A.M.M., Act. Cap. de 1494, sesión de 19 de julio, en J. TORRES FONTES, El Señorío..., p. 140.

76 Por ejemplo, la fuente de Pulpí, entre Lorca y Vera, o el caso de Fuente-Álamo, entre las tres jurisdicciones de Lorca, Murcia y Cartagena.

77 Archena, Ceutí, Alguazas y Cotillas están perpetuamente en pleito a lo largo del XVI. Vid. M.T. PÉREZ PICAZO; G. LEMEUNIER, El proceso de modernización de la Región Murciana (siglos XVI -XIX), Murcia, 1984, p. 74.

78 Archivo Histórico Provincial de Murcia (A.H.P.M.), Prot. 634, fols. Vr.-VIv.

79 El antiguo adelantado mayor de Murcia. En el pleito fueron progresivamente involucrándose tanto el adelantado mayor del reino en ese momento, Juan Chacón, como las hijas de Pedro Fajardo, doña Juana y doña Luisa

80 Archivo General de Simancas (A.G.S.), Sección Registro General del Sello (R.G.S.), fols. $8,95,90,213$ y 253. 
nieto, a través de una entrega de la propiedad y jurisdicción usurpadas que se debió producir antes de $1492^{81}$.

El problema de la repoblación no se había resuelto, o al menos eso parecen mostrar las fuentes. Molina Molina recoge el testimonio de Pedro Manuel, hijo de la censataria de Fortuna, Mencía López Fajardo (viuda de Fernán Sánchez Manuel), cuando se presenta ante los regidores murcianos, en 1455 para exponer que, desde hacía unos quince años, el lugar estaba siendo robado y destruido y permanecía despoblado, sus casas derribadas y sus tierras yermas ${ }^{82}$. Es difícil, entonces, imaginar una situación óptima para los baños, pero no sabemos que credibilidad otorgarle a estos testimonios de los censatarios comunicando el abandono de Fortuna, que por su reiteración más parecen ser la búsqueda de ventajas de tipo fiscal o el intento de obtener permisos para determinadas intervenciones, pues contradicen abiertamente otros testimonios, como la mencionada venta de 1466, que confirman un positivo resultado del proceso de repoblación. El hecho de que a Fray Nicolás, un fraile aragonés que acudía a los baños de Fortuna, le autorice el concejo "para traher tres caçadores porque maten caça para su provision" en 146183, no debe inducirnos a pensar en un particular abandono de la zona si tenemos en cuenta el momento de crisis que todo el reino de Murcia sufría esos años $\mathrm{y}$, en cambio, sí parece indicarnos la pervivencia en la tradición de visitar el manantial. En cualquier caso, a partir del tercer cuarto del siglo XV, Fortuna empieza a recuperarse o, como expresan Lemeunier y Pérez Picazo, empieza a resucitar como señorío tras un prolongado eclipse ${ }^{84}$. A ello contribuyó alguna donación concejil destinada a fomentar el despegue económico, como la que en 1491 le concedió al jurado Alfonso Hurtado "vn pedaço de tierra de secano que es del vso comun desta dicha çibdad" en los Baños de Fortuna ${ }^{85}$.

El concejo murciano ingresa entre los años 1459-60 y 1516-17 la cantidad de 4.050 maravedíes anuales del censo de los "baños e lugar de

81 A.G.S., R.G.S., fol. 49.

82 A.L. MOLINA MOLINA, El campo..., p. 76.

83 J. TORRES FONTES, “Alonso Fajardo y su señorío de Caravaca”, en Estudios de Historia de Caravaca. Homenaje al prof. Emilio Sáez, Murcia, 1998, p. 115.

84 M.T. PÉREZ PICAZO, G. LEMEUNIER, El proceso..., p. 48.

85 A.M.M., Act. Cap., 1491-92, fols. 80 r.-82 v.; A.L. MOLINA MOLINA, El campo..., p. 306. Donación confirmada en 1493, A.G.S., R.G.S., fol. 26; A. GOMARIZ MARÍN (ed.), Documentos de los Reyes Católicos (1492-1504), CODOM XX, Murcia, 2000, pp. 165-169. 
Fortuna" 86 y estas condiciones favorecerían sin duda a los propios baños, que en 1505 vuelven a aparecer mencionados en los documentos. Isabel de Orumbella, por entonces señora censataria de Fortuna ${ }^{87}$, escribe una carta al concejo de Murcia, quejándose de que los vecinos de Abanilla y los de Fortuna se bañan en la fuente de los baños y le perjudican directamente, al parar el agua que mueve su molino. La propia censataria relata todo el incidente $^{88}$ y ofrece algunos datos significativos. Al margen de la constatación documental, no muy frecuente, de la existencia de un molino de cubo en las inmediaciones de los baños que era abastecido por el agua del manantial ${ }^{89}$, se constata el primer empleo conocido del agua de los baños en las tareas de abastecimiento de la población, algo que será una constante en los siglos posteriores. Además, el documento es un testimonio de inestimable valor a la hora de confirmar el empleo de los baños de Fortuna por los musulmanes, al menos en función de la tradición oral de los primeros años del siglo XVI, y el mantenimiento de la costumbre de acudir a la fuente de aguas termales hasta los inicios de la Edad Moderna.

86 Vid. M.C. MELENDRERAS GIMENO, "Gastos e ingresos del Concejo Murciano en 1459-60", Miscelánea Medieval Murciana 1 (1973), p. 159; F. CHACÓN, "Una contribución al estudio de las economías municipales en Castilla. La coyuntura económica concejil murciana en el período 1496 -1517”, Miscelánea Medieval Murciana 3 (1977), p. 246; F. NAVARRO BELMONTE, "La hacienda concejil murciana 150 -1502", Miscelánea Medieval Murciana 16 (1990-91), p. 182.

87 Isabel de Orumbella volvería a intervenir en el desarrollo histórico de los baños de Fortuna en 1514, cuando tuvo lugar el pleito que mantuvo frente a su hija, Catalina de Cascales, en la Chancillería de Granada por la posesión de un tercio de sus pertenencias en la población. Real Chancillería de Granada (R.Ch.G.), 1514, Cab. 3, Leg. 1073, nº 13.

88 A.M.M., Caja 12, núm. 35 (Apéndice documental).

89 El molino de cubo esta documentado en la península Ibérica en fechas tempranas a partir del testimonio de Al-Qazwini; vid. traducción de Xavier Ballestín, 1848, II, p. 381, citado en M. ARGEMI RELAT, M. BARCELÓ, P. CRESSIER, H. KIRCHNER, C. NAVARRO, "Glosario de términos hidráulicos", en El agua y la agricultura en Al-Andalus, Madrid, 1995, p. 172. Este tipo de molino habría llegado posiblemente con la ocupación árabo-beréber desde Oriente, donde ha sido ampliamente documentado por la Arqueología; vid. R. MARTÍ, "Hacia una arqueología hidráulica: la génesis del molino feudal en Cataluña”, en Arqueología Medieval. En las afueras del medievalismo (M. Barcelo et al.), Barcelona, 1988, p. 168. 
A partir de entonces, el devenir de los baños está ampliamente documentado. Fortuna compraría su jurisdicción ${ }^{90}$ y le sería otorgada la Carta Puebla91, documento constitutivo de municipio que conforma su ser y condición, en 1631, pasando las instalaciones termales a convertirse en uno de los principales bienes propios del concejo. El primer arrendamiento de $1633^{92}$, que registra un depósito de 825 reales, sería sólo el principio: con el paso del tiempo y conforme se aceleró el proceso de apropiación del municipio, los baños comenzaron a ser arrendados directamente por su responsable, el concejo, y protagonizaron algunos momentos de esplendor. La continuidad estaba asegurada hasta la actualidad, en que el complejo termal, en su nueva ubicación, permanece en uso y explotación.

\section{APÉNDICE DOCUMENTAL}

1505, febrero, 22. Murcia.

Carta de Doña Isabel de Orumbella, señora de Fortuna, al concejo de Murcia, quejándose de que los vecinos de Abanilla y Fortuna se bañan en la fuente de Fortuna y le causan perjuicios en el molino que ella tiene, pidiendo que lo remedien.

A.M.M., caja 12, núm. 35.

Nobles y muy virtuosos sennores.

Donna Ysabel de Orumbella, sennora del lugar de Fortuna, beso las manos a vuestra merçed, a la qual fago saber commo yo, por avmentar e ennobleçer el dicho lugar de Fortuna, fize vn molino de cubo para moler trigo, el qual, al tiempo quel río desta çibdad viene ceçado, syrue mucho a esta çibdad, segund que es publico e notorio, y yo resçibo un grand agrauio de los vecinos de Hauanilla e del dicho lugar de Fortuna, el qual es este: que van a

90 Es muy significativo en este aspecto el documento del Archivo Municipal de Fortuna (A.M.F.), leg. 946, núm. 11, en el que el naciente concejo solicita la ayuda vecinal para hacer frente a la compra.

91 M. CANO GOMARIZ, Carta puebla de Fortuna (edición y comentario a cargo de María Cano Gomáriz), Murcia, 1994.

92 A.M.F., leg. 516, núm. 25, de 1633-I-5. 
la fuente e bannos de Fortuna donde viene el agua para el dicho molino e por se bannar, segund que seyendo moros lo fazian, fazen parada en la açequia que viene al dicho molino e tomanme el agua, de manera que el molino, por ser de cubo como es, en que talle su agua commo viene de filo luego para el dicho molino y fasta que se torna a hinchar el dicho cubo, el dicho molino está parado, de lo qual yo resçibo mucho danno e agrauio.

Por este agrauio que yo resçibo no me dexa ni puedo tener molino para el dicho molino y pues a vuestra merçed pertenesçen el castigo e remedio dello, vmillemente les suplico lo mande remediar e castigar, poniendo penas al que fizyere parada en la dicha agua o la detuviere en qual quier manera, pues que el dicho molino, commo dicho tengo, es para servicio desta çibdad como para el dicho lugar de Fortuna.

Otrosy notifico a vuestra merçed commo los dichos vecinos de Fortuna, seyendo vasallos e vecinos desta cibdad, son muy fatigados e cohechados de las guardas de almoxarifazgo, que cada vez que viahan a esta çibdad qual quier cosa para vender, les fazen yr al aduana commo si fuesen estrangeros y de lo que sacan desta cibdad para Fortuna, por que no lleuan aluala, les cohechan una vez tres maravedis, otra vez XVIII, otra vez diez maravedis, segund lo que sacan. Y sy a esto vuestra merçed ha de dar lugar, muy poco aprouecha el previllejo e franquiza que la çibdad tiene.

Suplico a vuestra merçed en todo lo mande proueer e remediar, pues que tienen el poder para ello, y en ello me farán a mi sennalada merçed.

Nuestro señor, las nobles y muy virtuosas personas de vuestras merçedes guarde e acreçiente como de vuestra merçed es deseado.

// v. En concejo, siendo XXII de febrero de DV, por Francisco de Austo, en nombre de donna Ysabel de Urunbella.

Y los dichos señores acordaron y mandaron que de aquí adelante persona alguna no sea osada de fazer parada ni enbaraço alguno en la dicha açequia de Fortuna ni en el banno dél, so pena de çien maravedis por cada vez, el terçio para el acusador, el terçio para el sennor del molino y el terçio para la çibdad y mandaron se pregone en el dicho lugar de Fortuna. 